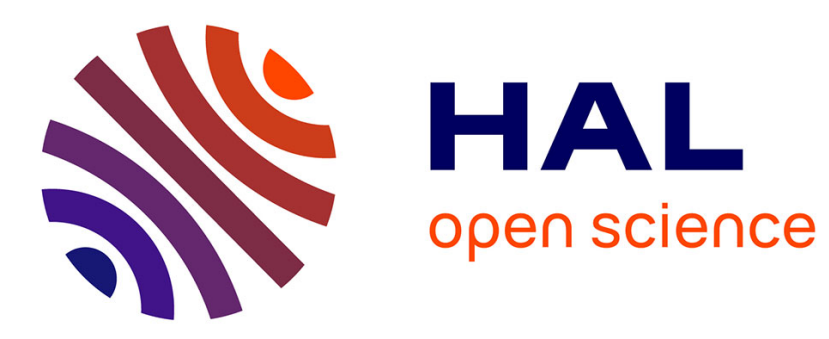

\title{
A promising "metastable" liquid crystal stationary phase for gas chromatography
}

Faïza Ammar Khodja, Patrick Sassiat, Mohamed Hanafi, Didier Thiebaut, Jerome Vial

\section{- To cite this version:}

Faïza Ammar Khodja, Patrick Sassiat, Mohamed Hanafi, Didier Thiebaut, Jerome Vial. A promising "metastable" liquid crystal stationary phase for gas chromatography. Journal of Chromatography A, 2020, 1616, pp.460786. 10.1016/j.chroma.2019.460786 . hal-02568593

\section{HAL Id: hal-02568593 \\ https://hal.science/hal-02568593}

Submitted on 9 May 2020

HAL is a multi-disciplinary open access archive for the deposit and dissemination of scientific research documents, whether they are published or not. The documents may come from teaching and research institutions in France or abroad, or from public or private research centers.
L'archive ouverte pluridisciplinaire HAL, est destinée au dépôt et à la diffusion de documents scientifiques de niveau recherche, publiés ou non, émanant des établissements d'enseignement et de recherche français ou étrangers, des laboratoires publics ou privés. 


\title{
A promising "metastable" liquid crystal stationary phase for gas chromatography
}

\author{
Faïza Ammar Khodja ${ }^{\mathrm{a}, *}$, Patrick Sassiat $^{\mathrm{b}}$, Mohamed Hanafic ${ }^{\mathrm{c}}$, Didier Thiebaut ${ }^{\mathrm{b}}$, Jérôme Vial ${ }^{\mathrm{b}}$ \\ a Laboratoire de Chromatographie, Faculté de Chimie, Université des Sciences et de la Technologie Houari Boumediene (USTHB), BP 32 El Alia, Bab Ezzouar, \\ 16111, Alger, Algeria \\ ${ }^{\mathrm{b}}$ Laboratoire Sciences Analytiques Bioanalytiques et Miniaturisation (LSABM), UMR CNRS 8231 - Chimie Biologie Innovation, ESPCI-Paris, PSL Research \\ University. 10, rue Vauquelin 75231, Paris CEDEX 05, France \\ ${ }^{c}$ Laboratoire de Sciences et Ingénierie de la Matière Molle (SIMM), UMR CNRS 7615, ESPCI-Paris, PSL Research University. 10, rue Vauquelin 75231, Paris \\ CEDEX 05, France
}

\section{A R T I C L E I N F O}

Article history:

Received 17 September 2019

Revised 11 December 2019

Accepted 11 December 2019

Available online 12 December 2019

Keywords:

Geometric selectivity

Mesophase

Metastable liquid crystal

Supercooled liquid crystal

Capillary gas chromatography
A B S T R A C T

\section{Introduction}

In gas chromatography (GC), commercially available stationary phases are essentially derived from polydimethyl siloxane (PDMS) and polyethylene glycol (PEG). These phases can be considered as the "conventional GC stationary phases". They allow the discrimination of most solute probes with various polarities. They fulfill most of current requirements but sometimes they show limi-

\footnotetext{
* Corresponding author.

E-mail address: f1amk@yahoo.fr (F. Ammar Khodja).
}

tations in the differentiation of similar molecules possessing different spatial structures as geometric isomers of position and cistrans isomers. Previous studies have already shown the potential of liquid crystal stationary phases (LCSPs) in the separation of geometric isomers [1-5]. Indeed, in the liquid crystal state, called also mesophase or meogenic phase, the molecules are in an intermediate physical state between the solid and the liquid and can move freely in space while maintaining at least one degree of order. In the mesophase, the molecules are oriented, spontaneously, in a well-defined direction which confers thus to the stationary phase a geometric selectivity. The mesogenic molecules can be organized in a nematic $(\mathrm{N})$, smectic $(\mathrm{Sm})$ or cholesteric $(\mathrm{Ch})$ structure 
[1-13] and depending on the molecular association, the mesophase shows a specific geometric selectivity [1-5]. A representation of the nematic, smectic and cholesteric structures of liquid crystals is given in the supplementary part (Fig. S1). In literature, frequent applications of liquid crystals in GC used thermotropic LCSPs when the mesophase appears by a simple modification of the temperature. Most often, these LCSPs are used in the "stable" mesophase appearing at rather high temperature, above the solid-liquid crystal transition where the best chromatographic effects are generally obtained [3]. However, sometimes LCSPs could be used in the solid (S) or the liquid state (L) [3]. The possibility of using supercooled liquid crystal phase was also mentioned for the analysis of the most volatile compounds. However, since the end of the 90s, this technique has seldom been used [14-19]. In general, the authors reported that the liquid crystal state was sufficiently stable to be used as a continuation of the mesophase to lower temperature; however no information was available on how long it remained stable in this state. Only the work of Witkiewicz et al. [15] referred to a period of several hours without any other explanation. The stability of a liquid crystal in a supercooled state was studied, in one recent work [20], over more than one day but the recrystallization occurred from the first hours of its appearance. The study of Blokhina et al. [21] was the only recent work found using a LCSP in supercooled conditions. Indeed, it is not common, to work in these conditions. In the present study, we propose a new thermotropic liquid crystal stationary phase with a nematic mesophase which has the originality of being stable for several weeks in a state of supercooling. Thus, it offers original separation possibilities at relatively low temperatures, compatible with the separation of volatile compounds. Thereafter, firstly, the structure of the new synthesized liquid crystal will be described. Then, the experimental conditions of its characterizations will be given. Its thermal stability will be discussed upon the results obtained by thermogravimetric analysis (TGA) and differential scanning calorimetry (DSC). The transition temperatures of the new liquid crystal and particularly the presence of the supercooled liquid crystal state observed by hot-stage optical microscopy (HSM), DSC and GC analysis will be compared. Finally, the analytical performances of the new liquid crystal used as stationary phase in GC analysis will be demonstrated in both the stable liquid crystal phase and the metastable state which corresponds to the liquid crystal in supercooling conditions.

\section{Experimental}

\subsection{Molecular structure of the new stationary phase}

The chemical structure of the new synthesized material, 1,4- bis (4-bromohexyloxy benzoate) phenyl (BHOBP), used in this work, is shown in Fig. 1. It contains a rigid core with carboxylic ester bridges and two para terminal bromohexyloxy flexibles chains. To our knowledge, no application of LCSPs containing a bromine atom has been reported in literature. It is important to keep in mind that during the first applications of liquid crystal phases in chromatog- raphy, some of them had shown a lack of stability over time and they did not have a large range of temperature to work with. More recently, several high molecular weight monomeric LCSPs as well as polymeric LCSPs have been synthesized, to increase the stability of the mesophase and to make it appear in a wide temperature range [3]. In our study, BHOBP LCSP which is a monomer of a high molecular weight showed a great stability through the different GC separations achieved during the three last years of its use. The purity of the synthesized BHOBP was controlled by $1 \mathrm{D}{ }^{1} \mathrm{H}$ NMR; the corresponding chemical shifts with a brief synthesis protocol are reported in Fig. S2 in the supplementary part. The molecular structure was confirmed by high resolution mode ESI MS (Electrospray Ionization mass spectrometry) used by directly introducing a solution of BHOBP into a Bruker microTOF-QII spectrometer. MS spectrum obtained is given in the supplementary part in Fig. S3 with a description of the analyzed solution preparation.

\subsection{Thermal analysis}

A hot-stage optical microscope, the "polarized light microscope Olympus BH-2-Central processor Mettler FP80", was used to observe the thermal transitions of BHOBP and classify the texture of the new liquid crystal phase. A thermogravimetric analysis was performed on a TGA Q50 device from TA Instruments-USA, with $12.93 \mathrm{mg}$ of BHOBP to control its thermal stability. The transition temperatures were also evaluated using a TA Discovery scanning calorimeter from TA Instruments-USA and compared to the values obtained by microscopy and inverse gas chromatography (IGC).

\subsection{Column preparation and method for GC analysis}

To carry out gas chromatographic investigations using BHOBP as stationary phase, a capillary column $(30 \mathrm{~m} \times 0.32 \mathrm{~mm}$ i.d. $)$ was prepared. A fused silica pre-treated tube of intermediate polarity, purchased from Supelco (Bellefonte, PA, USA- Reference $\mathrm{N}^{\circ}$ 25774: lot $\mathrm{N}^{\circ}$ 54294), was coated, in the laboratory, by the dynamic method. Firstly, proceeding at room temperature under nitrogen gas, a solution of BHOBP in $\mathrm{CHCl}_{3}$ of $6 \%(\mathrm{w} / \mathrm{v})$ in $\mathrm{g} / \mathrm{mL}$, was pushed through the silica tube. Then the column was dried for one night under the same conditions. Finally, a series of temperature programming was conducted to condition the column as follows: heating at $+5{ }^{\circ} \mathrm{C} / \mathrm{min}$ from $30{ }^{\circ} \mathrm{C}$ to $150{ }^{\circ} \mathrm{C}$, isothermal at $150{ }^{\circ} \mathrm{C}$ for $3 \mathrm{~h}$, heating at $+5{ }^{\circ} \mathrm{C} / \mathrm{min}$ from $150{ }^{\circ} \mathrm{C}$ to $180{ }^{\circ} \mathrm{C}$, isothermal at $180{ }^{\circ} \mathrm{C}$ during $48 \mathrm{~h}$ and rapid cooling of the column to $30^{\circ} \mathrm{C}$. The BHOBP column was thus ready to be used. IGC and analytical GC experiments were performed with an Agilent Technologies 7820A GC system equipped with an FID and a split/splitless injector; the carrier gas flow was $1 \mathrm{~mL} / \mathrm{min}$ at different temperatures. Helium (Alphagaz 1 from Air Liquide) was used as carrier gas; for FID, hydrogen 5.0 (purity > 99.999\%) from MESSER, azote 6.0 (purity $\geq$ 99.9999\%) from MESSER and air provided from a central network (ESPCI) connected to a hydrocarbon trap (model BHT-2 from Agilent) were used. The GC apparatus was piloted by GC ChemStation Rev.B.04.02 SP1 [208] software, Agilent Technology [2001-2010].

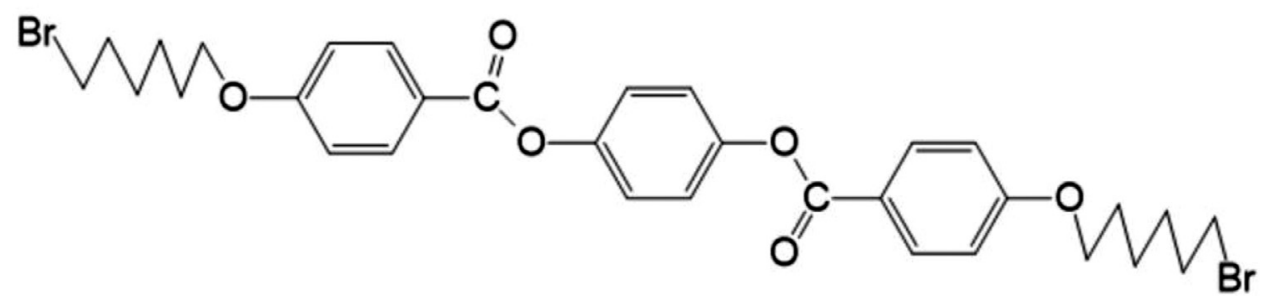




\section{Table 1}

Molecular structure and some characteristics (name, abbreviation, CAS number, boiling point, origin, grade and chemical formulas) of the probe solutes used in GC.

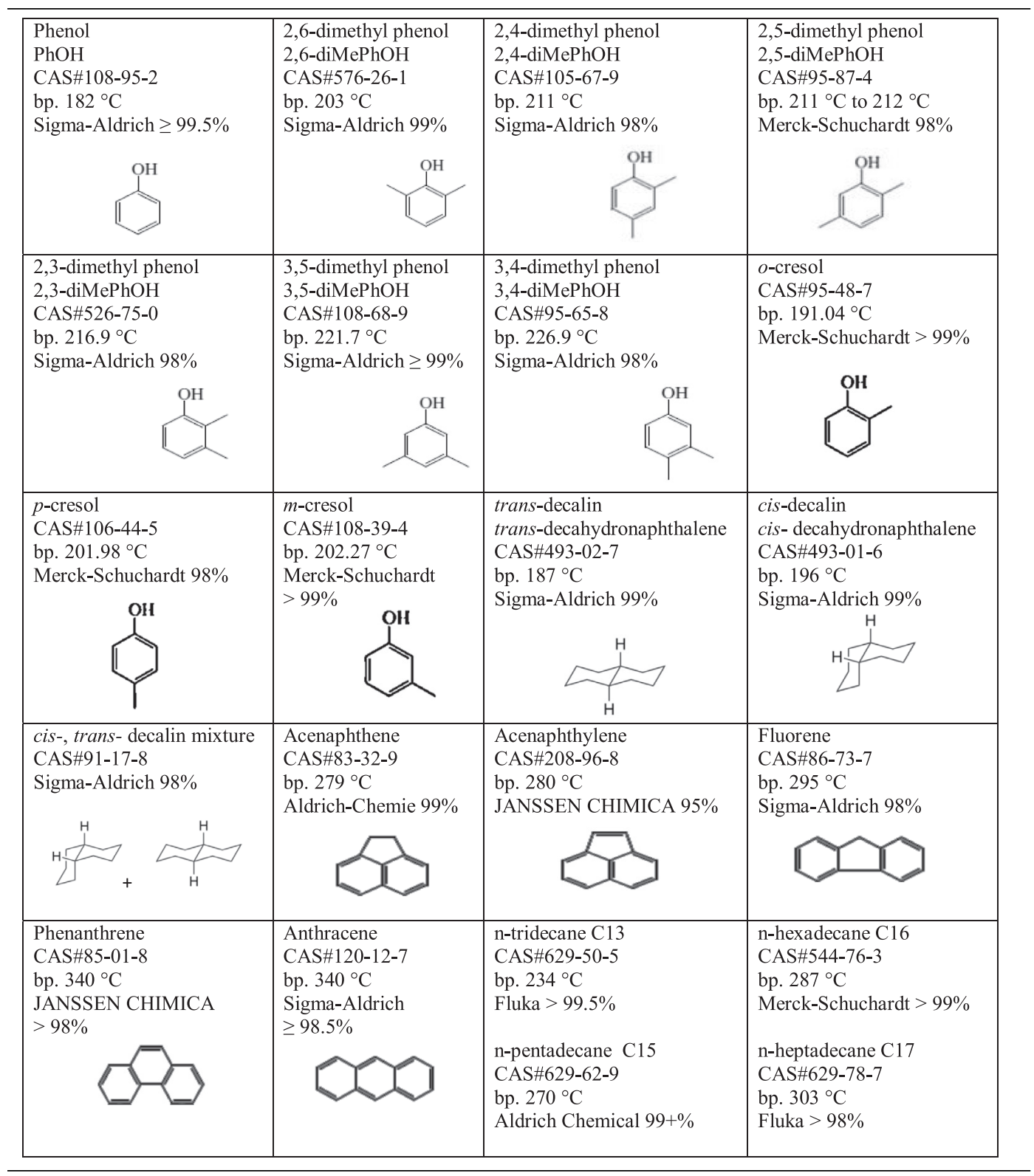

\subsection{Chemicals}

The solutes used in chromatographic experiments were purchased from Sigma Aldrich, Merck Schuchardt, Aldrich, JANSSEN CHIMICA and Fluka. Their purity was mostly around $98 \%$ or $99 \%$. The chemical structures of the tested solutes and some related properties are given in Table 1.

\section{Results and discussion}

\subsection{Thermal properties}

\subsubsection{Hot stage optical microscopy (HSM)}

The thermotropic properties of BHOBP and the nature of its different physical states were confirmed by HSM during heating and cooling steps at $\pm 10^{\circ} \mathrm{C} / \mathrm{min}$ between $20^{\circ} \mathrm{C}$ and $210{ }^{\circ} \mathrm{C}$. Upon heating, the sample showed a solid-nematic liquid crystal transition (the melting point) at around $125^{\circ} \mathrm{C}\left( \pm 1{ }^{\circ} \mathrm{C}\right)$ and a nematic-liquid transition (the clearing point) about $204^{\circ} \mathrm{C}\left( \pm 1{ }^{\circ} \mathrm{C}\right)$. The HSM analysis also showed, during the cooling step, the presence of a supercooled nematic state which persisted until the temperature was $106.5^{\circ} \mathrm{C}\left( \pm 8.5^{\circ} \mathrm{C}\right)$. A representative diagram of the different transitions observed during a heating-cooling cycle operated on BHOBP is given in the supplementary section (Fig. S4).

\subsubsection{Thermogravimetric analysis (TGA)}

This experiment allowed us to estimate the maximum heating limit temperature before thermal degradation of the material that leads to a loss of mass. BHOBP showed a thermal stability until around $271{ }^{\circ} \mathrm{C}$ (loss of mass $<0.2 \%$ ). The corresponding TGA thermogram is given in the supplementary part (Fig. S5).

\subsubsection{Differential scanning calorimetry (DSC)}

First BHOBP DSC experiments showed new results which were not revealed microscopically. When a sample of $6.1 \mathrm{mg}$ of BHOBP was heated from $20^{\circ} \mathrm{C}$, in the solid state, to $260{ }^{\circ} \mathrm{C}$ at $+10{ }^{\circ} \mathrm{C} / \mathrm{min}$, 


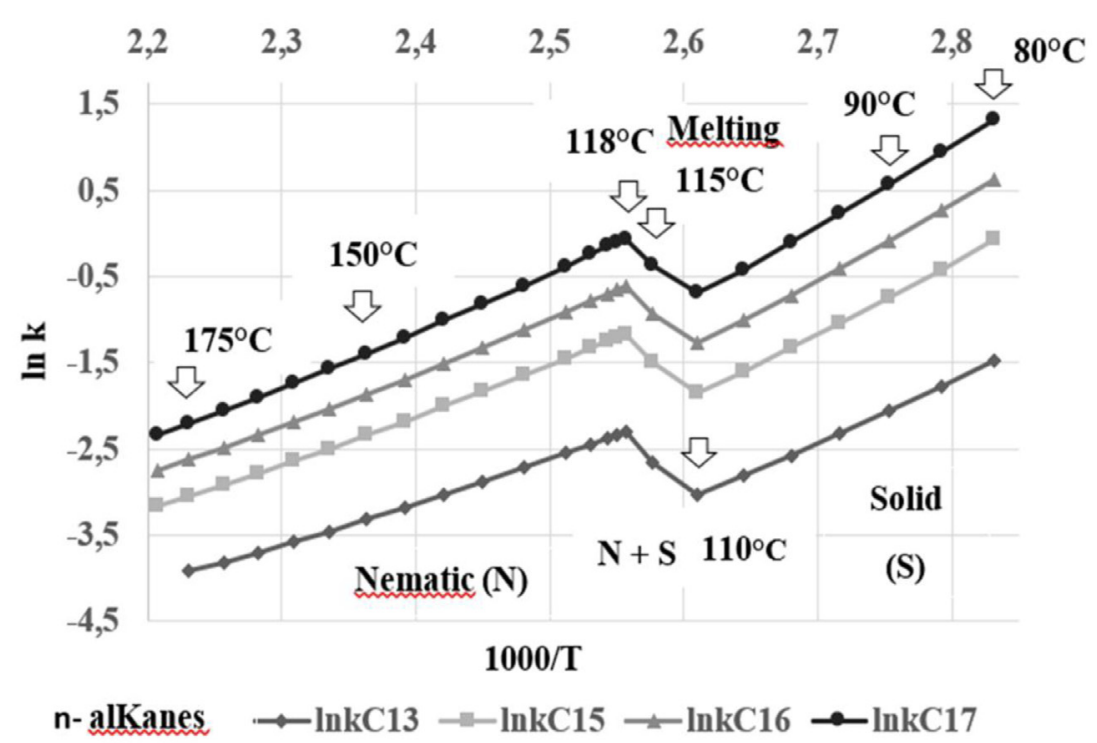

\section{$\mathrm{k}$ : Retention factor of the probe solute \\ $\mathrm{T}$ : Absolute temperature of BHOBP GC column}

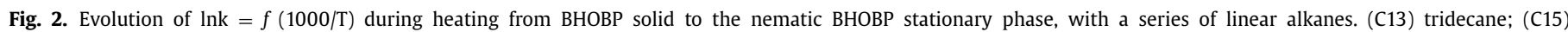
pentadecane; (C16) hexadecane; (C17) heptadecane.

an endothermic peak was obtained at the melting point, $123.97{ }^{\circ} \mathrm{C}$ $(93.77 \mathrm{~J} / \mathrm{g})$. The clearing point was observed with the appearance of a weakly endothermic peak at $199.34{ }^{\circ} \mathrm{C}(3.54 \mathrm{~J} / \mathrm{g})$. The clearing temperature recorded by DSC was about $5{ }^{\circ} \mathrm{C}$ less than the value obtained by HSM. That can be explained by observing the difference between the two characterization technics. Indeed, through the optical microscope the clarification was observed at the end of the transformation. The temperature given by DSC was obtained at the maximum of the peak on the thermogram which corresponded to the center of the clarification rather than at the end of this physical transformation. Therefore, these first DSC results were in agreement with the transitions observed by microscopy. However, once the previously heated liquid was cooled down to room temperature and heated again, a significant shift of the melting and clearing transitions to lower values was observed. This result demonstrated a structural change in BHOBP molecules. Other solid samples were heated until $205{ }^{\circ} \mathrm{C}$, cooled to room temperature then heated again to $205^{\circ} \mathrm{C}$. After a first heating of BHOBP solid to the liquid state, the next melting and clearing points were shifted to lower temperatures but less than previously. These last experiments confirmed that the BHOBP undergoes a structural change as soon as the clearing point temperature is exceeded.

The next DSC experiments consisted of several heating and cooling cycles at $\pm 10^{\circ} \mathrm{C} / \mathrm{min}$, with a sample of $6.4 \mathrm{mg}$ of BHOBP, between room temperature and $180{ }^{\circ} \mathrm{C}$ (below the nematic- liquid transition). The endothermic peak of melting point was observed with a maximum of nearly the same temperature, around $124{ }^{\circ} \mathrm{C}$. This value confirmed the melting point observed microscopically. An example of DSC thermograms observed, after cooling the first liquid BHOBP resulting from the synthesized crystals, during a cycle of heating-cooling between $50{ }^{\circ} \mathrm{C}$ and $180^{\circ} \mathrm{C}$, is reported in the supplementary section (Fig. S6). The melting peak reached was larger than the first melting peak observed with the starting BHOBP crystals. In fact, melting started at around $120{ }^{\circ} \mathrm{C}$, below the maximum peak at $124{ }^{\circ} \mathrm{C}$ (Fig. S6). The width of this peak depends, clearly, on how BHOBP crystallized. It seems obvious that the smaller the solid specific surface area is, the slower the energy exchanges to allow the solid-liquid crystal transition should be and the wider the transition peak becomes.

In these conditions, it appears that the chemical structure of BHOBP does not change through successive heating-cooling cycles. The characterization of BHOBP when used as a stationary phase for GC applications was thus limited to the maximum temperature of $180{ }^{\circ} \mathrm{C}$.

On the other hand, when the stable nematic mesophase, reached above $120{ }^{\circ} \mathrm{C}$, was heated to $180{ }^{\circ} \mathrm{C}$ then cooled down, a supercooled liquid crystal state was present until around $115{ }^{\circ} \mathrm{C}$ when an exothermic peak of crystallization was observed (Fig. S6).

\subsubsection{Inverse gas chromatography (IGC)}

In previously published studies [22-24,20,25-28,3,5], it was demonstrated that when the liquid crystal stationary phase film was thick enough, using appropriate support and probe solutes, the IGC allowed them to find almost the same transitions as those observed by DSC and microscopy.

In this work, the solid-nematic phase transition temperature (the melting point) was determined using a series of n-alkanes probe solutes (C13, C15, C16, C17) injected in isothermal conditions, at different temperatures ranging from $80{ }^{\circ} \mathrm{C}$ to $180{ }^{\circ} \mathrm{C}$. In Fig. 2, Van't Hoff plots for the selected alkanes are given. The corresponding plots were straight lines in two temperature ranges, from $80{ }^{\circ} \mathrm{C}$ to $110{ }^{\circ} \mathrm{C}$ in the solid phase and in the nematic phase above $118{ }^{\circ} \mathrm{C}$. The melting point was revealed, with all the solutes, in the same temperature range, between $110{ }^{\circ} \mathrm{C}$ and $118{ }^{\circ} \mathrm{C}$, when the retention factor increased during the column heating. These results were also observed directly through the recorded chromatograms. Some examples are reported in Fig. 3. A classical evolution was observed, as already described in literature for the retention when LCSPs were melted [22-24,20,25-28,3,5]. Indeed, from $80{ }^{\circ} \mathrm{C}$ to $110{ }^{\circ} \mathrm{C}$, in the solid, the retention decreased when the temperature increased. During the melting transition, when the column was heated from $110{ }^{\circ} \mathrm{C}$ to $118{ }^{\circ} \mathrm{C}$, a progressive increase of retention along with an improvement of selectivity were observed. Then, when heated from $118{ }^{\circ} \mathrm{C}$ to $180{ }^{\circ} \mathrm{C}$, the stationary phase was in the nematic liquid crystal state and retention de- 

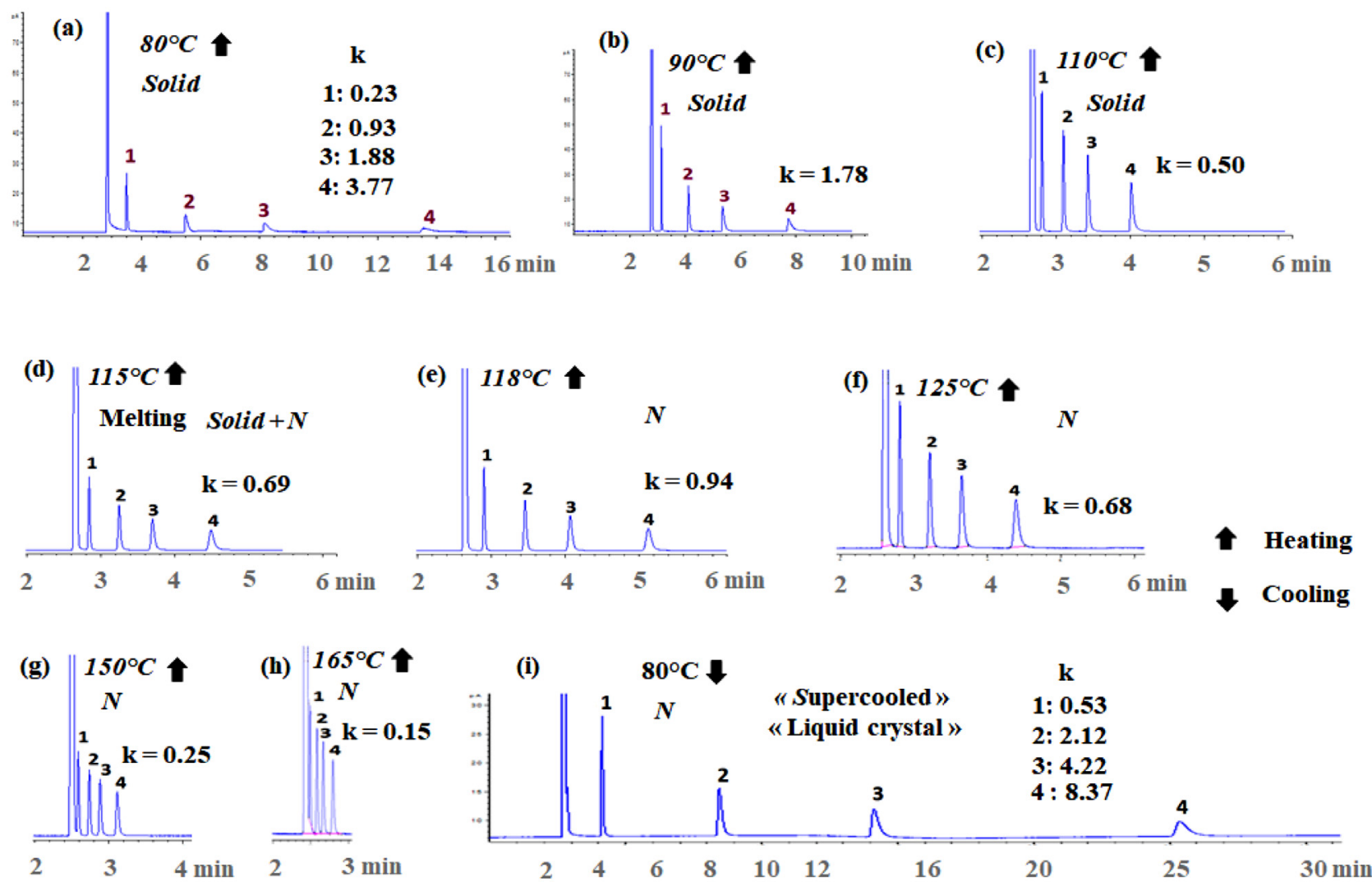

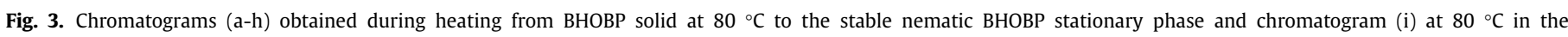

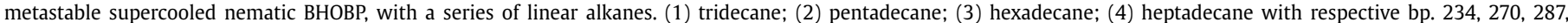
$303{ }^{\circ} \mathrm{C}$.

creased again when increasing the temperature. IGC results were thus in agreement with HSM and DSC experiments confirming the melting point of the stationary phase.

In the following part, crystallization conditions of the nematic phase in the capillary column were discussed. After heating to $180{ }^{\circ} \mathrm{C}$, the column was, firstly, cooled to $40{ }^{\circ} \mathrm{C}$ and maintained at that temperature for $15 \mathrm{~min}$ before heating again to $80{ }^{\circ} \mathrm{C}$. The retention factors were the same as in the former experiment in the solid phase obtained at $80{ }^{\circ} \mathrm{C}$ after cooling the column to $40{ }^{\circ} \mathrm{C}$ for the night. In these conditions, the stability of the solid state was also confirmed. Indeed, when the n-alkanes probe solutes ( $\mathrm{C} 13$, $\mathrm{C} 15, \mathrm{C} 16, \mathrm{C} 17)$ were injected 24 times, over a period of 8 days, in the solid at $80{ }^{\circ} \mathrm{C}$, similar retention times (tr) and retention factors $(\mathrm{k})$ were always obtained for the whole of them (RSD $(\operatorname{tr})=0.1 \%$ and $\operatorname{RSD}(\mathrm{k})=0.2 \%)$. When BHOBP was recrystallized again, the repeatability of retention times and retention factors in the solid at $80{ }^{\circ} \mathrm{C}$ was confirmed (RSD (tr) and RSD $\left.(\mathrm{k})<0.5 \%\right)$.

It has also been confirmed that BHOBP coated onto the surface of the capillary column maintained the same behavior with the probe solutes, in the nematic phase, by repeating the heatingcooling cycle between $40{ }^{\circ} \mathrm{C}$ and $180{ }^{\circ} \mathrm{C}$. The repeatability of $\mathrm{C} 13$, $\mathrm{C} 15, \mathrm{C} 16, \mathrm{C} 17 \mathrm{n}$-alkanes retention times and retention factors when injected at $118{ }^{\circ} \mathrm{C}$ and $180{ }^{\circ} \mathrm{C}$ was estimated. RSD (tr) and RSD (k) values were less than $0.1 \%$ at $118{ }^{\circ} \mathrm{C}$ and less than $0.5 \%$ at $180{ }^{\circ} \mathrm{C}$.

The thermal stability of BHOBP was thus demonstrated when used below the maximum temperature of $180{ }^{\circ} \mathrm{C}$, as it was proven before by DSC analysis. The total crystallization of the mesophase when the column was cooled to $40{ }^{\circ} \mathrm{C}$ was also confirmed.

\subsubsection{Highlighting a new supercooled liquid crystal by GC}

In our study, the presence of a supercooled liquid crystal state was observed by microscopy and DSC. We decided to control the presence of the supercooled state when BHOBP was deposited into the chromatographic column. The presence of such a state would indeed make possible to work at low temperature, by taking advantage of the geometric selectivity of the nematic phase. We proceeded as follows: The column was heated from $40{ }^{\circ} \mathrm{C}$ to $150{ }^{\circ} \mathrm{C}$ to exceed the melting temperature revealed by IGC $\left(110{ }^{\circ} \mathrm{C}\right.$ $118{ }^{\circ} \mathrm{C}$ ), and then the column was cooled to $80{ }^{\circ} \mathrm{C}$. The Fig. 3 (a) and (i) represent chromatograms of n-alkanes mixture (C13, C15, $\mathrm{C} 16, \mathrm{C} 17$ ), respectively, in the solid phase at $80{ }^{\circ} \mathrm{C}$ (during the heating step) and in the supercooled nematic BHOBP at $80{ }^{\circ} \mathrm{C}$ (during the cooling step). We can see the difference of retention between the solid and the liquid crystal phase. There is an increase of $130 \%, 128 \%, 124 \%$ and $122 \%$ of the retention factor, respectively, for tridecane, pentadecane, hexadecane and heptadecane. The stability of this supercooled state obtained at $80{ }^{\circ} \mathrm{C}$ was tested regularly, keeping the temperature at $80{ }^{\circ} \mathrm{C}$, over a period of about 7.5 weeks. For this experiment, two mixtures of probe solutes were used, the $\mathrm{C} 13, \mathrm{C} 15, \mathrm{C} 16, \mathrm{C} 17$ n-alkanes mixture used before and a mixture of phenolic derivatives composed of phenol $(\mathrm{PhOH})$ and the following isomers of dimethyl phenol (diMePhOHs): 2,6-diMePhOH, 2,4-diMePhOH, 2,5-diMePhOH, 2,3diMePhOH, 3,5-diMePhOH, 3,4-diMePhOH. For each mixture, the same chromatograms were obtained for all the injections, proving the thermal stability of the supercooled BHOBP at $80{ }^{\circ} \mathrm{C}$, over a period of 7.5 weeks. The solution of n-alkanes was injected 14 times, giving always similar retention times and retention factors (RSD $(\operatorname{tr})<1.5 \%$ and $\operatorname{RSD}(\mathrm{k})==1.6 \%$ ). The phenolic derivatives mixture was injected 17 times, also showing similar retention times and retention factors for all the probe solutes (RSD $(\operatorname{tr})<2.5 \%$ and RSD $(\mathrm{k})<3.5 \%$ ). This experiment was stopped at 7.5 weeks because of a power failure, not because the stationary phase had changed. 
(a) $80^{\circ} \mathrm{C}$

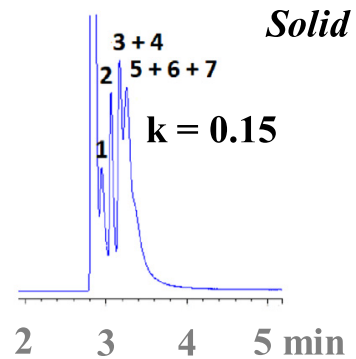

(b) $118^{\circ} \mathrm{C} \uparrow \mathrm{N}$

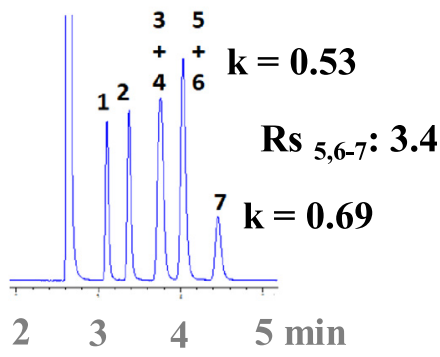

(c) $80^{\circ} \mathrm{C} \rightleftharpoons \mathrm{N}$

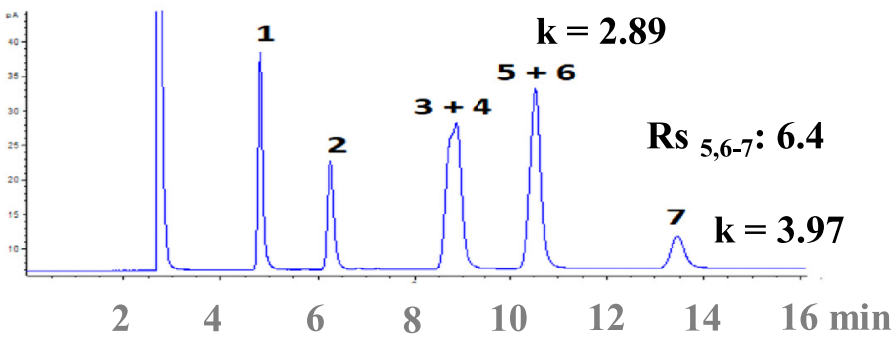

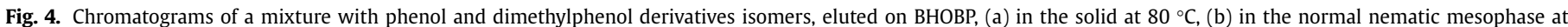

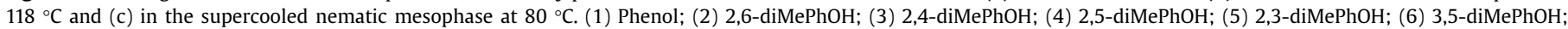
(7) 3,4-diMePhOH.

The spontaneous recrystallization of the supercooled phase in the column should occur at a temperature below $80^{\circ} \mathrm{C}$. By microscopy and DSC, we had found a total recrystallization of the supercooling state between $98^{\circ} \mathrm{C}$ and $115^{\circ} \mathrm{C}$. It seems that when the BHOBP is deposited in the column the supercooled phase is stable at lower temperature than in HSM and DSC conditions of experiment. This observation indicates specific interactions between the mesogenic molecules of the liquid crystal and the internal surface of the capillary column.

To ensure that during the previous experiments the stationary phase was not degraded and did not undergo excessive bleeding phenomenon, the column was cooled to $40{ }^{\circ} \mathrm{C}$ and maintained for $15 \mathrm{~min}$, then returned to the solid state. The mixtures of $n$ alkanes and phenol derivatives used before were then analyzed at $80{ }^{\circ} \mathrm{C}$ after heating the column directly from $40{ }^{\circ} \mathrm{C}$ : The same chromatograms as in the first heating in the solid phase at $80{ }^{\circ} \mathrm{C}$ were obtained. Then, the column was heated just above the melting point and cooled down again to $80{ }^{\circ} \mathrm{C}$ and the same chromatograms as in the first supercooled experiment were obtained.

The supercooled liquid crystal state at $80^{\circ} \mathrm{C}$ could henceforth be considered for the separation of different volatile mixtures.

It is interesting to note that, in the past, several synthesis studies have been conducted to find a way to obtain low-melting liquid crystals with broad mesophase range [29]. In our work, the presence of the supercooled nematic state allowed us to enlarge considerably the temperature range where BHOBP can be used. Besides, according to our knowledge it is the first paper in which a very stable supercooled state of LCSP is described.

\subsection{Gas chromatography performances of the LCSP}

For all the solutes tested, BHOBP showed fewer retention in the solid phase than in the nematic phase. The chromatographic performances of BHOBP can be illustrated through some examples.
The following first two examples will show the ability of the stable nematic liquid crystal appearing above the melting point, to separate compounds of relatively low volatility, by taking advantage of its geometric selectivity.

\subsubsection{Analysis of phenol derivatives}

The phenol derivatives were not resolved in the solid phase at $80{ }^{\circ} \mathrm{C}$, retention factors were below 0.15 (Fig. 4a). The best results were obtained at $118{ }^{\circ} \mathrm{C}$, just at the beginning of the existence of the stable nematic mesophase, where the retention and the selectivity of BHOBP were improved with many probe solutes (Fig. 4b). In the nematic at $118{ }^{\circ} \mathrm{C}$, the selectivity between 2,3-diMePhOH (5), 3,5-diMePhOH (6) and 3,4-diMePhOH (7): $\alpha_{5,6 / 7}$ was 1.3 and the resolution Rs 5,6/7 $=3.4$ (respective retention factors were $\mathrm{k}_{5,6}=0.53$ and $\mathrm{k}_{7}==0.69$ ). The solution of phenol derivatives was injected in the supercooled nematic BHOBP at $80{ }^{\circ} \mathrm{C}$ (Fig. 4c). As predicted, the retention was higher in the liquid crystal phase at $80{ }^{\circ} \mathrm{C}$ than in the solid at $80{ }^{\circ} \mathrm{C}$. There was an increase of the retention factor of about $1827 \%$ and $2547 \%$, respectively, for $2,3-$ diMePhOH (5) / 3,5-diMePhOH (6) and 3,4-diMePhOH (7). In the supercooled BHOBP at $80{ }^{\circ} \mathrm{C}$, the selectivity $\alpha_{5,6 / 7}$ became 1.37 and the resolution $\mathrm{Rs}_{5,6} / 7=6.4$ (respective retention factors were $\mathrm{k}_{5,6}=2.89$ and $\mathrm{k}_{7}==3.97$ ). However, in these conditions, solutes which coeluted at $118{ }^{\circ} \mathrm{C}$ (2,4-diMePhOH (3) / 2,5-diMePhOH (4) and 2,3-diMePhOH (5) / 3,5-diMePhOH (6)) were still not separated and the analysis was much longer than at $118{ }^{\circ} \mathrm{C}$ in the stable nematic BHOBP.

\subsubsection{Analysis of polyaromatic hydrocarbons (PAHs)}

The elution of five PAHs, acenaphthene (1), acenaphthylene (2), fluorene (3), phenanthrene (4) and anthracene (5), tested in the solid phase at $80{ }^{\circ} \mathrm{C}$ led to large asymmetric peaks (Fig. 5a), $\mathrm{As}_{1,2}=0.67 ; \mathrm{As}_{3}==5$ and $\mathrm{As}_{4,5}=15$. In these conditions, mainly because of the close boiling temperatures of acenaphthene and 

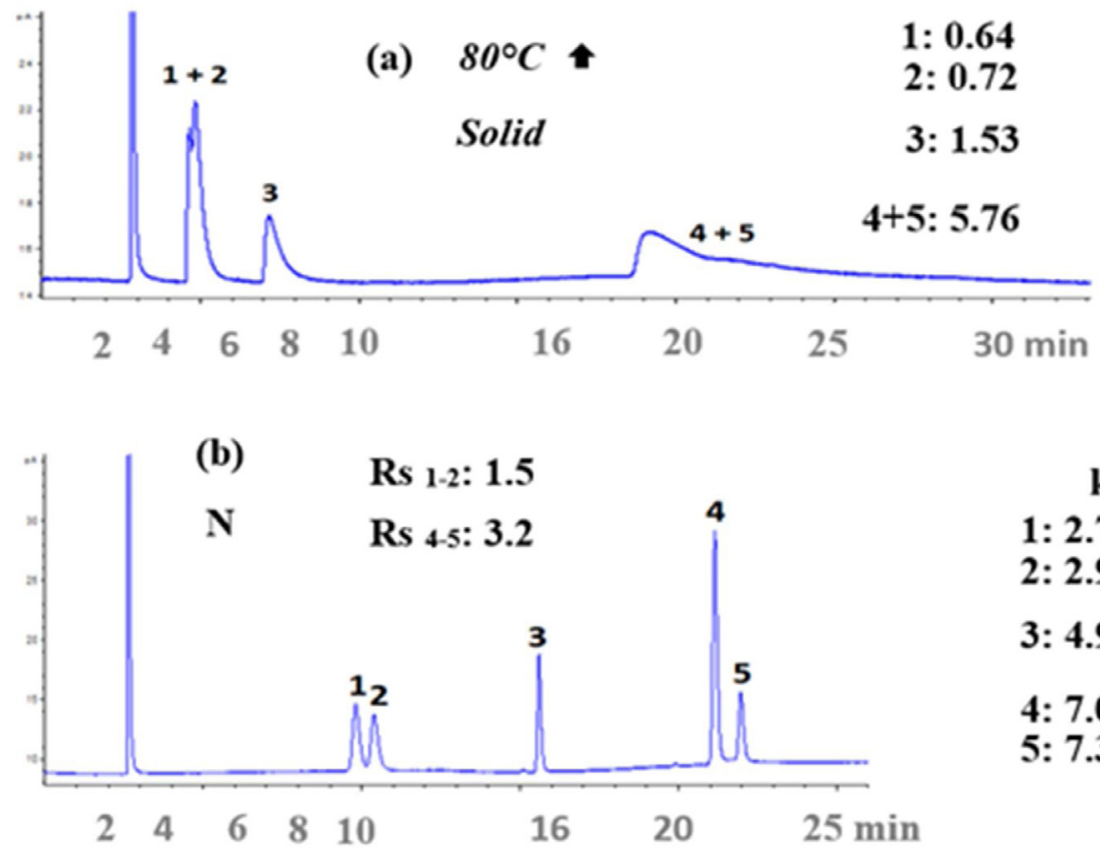

k

1: 2.73

2: 2.95

3: 4.93

4: 7.03

5: 7.35

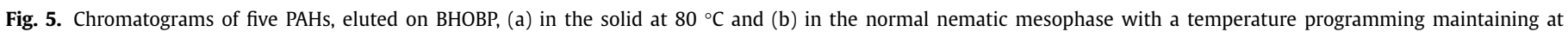

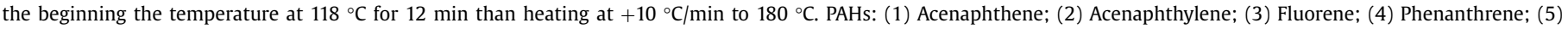
Anthracene.

acenaphthylene and of geometric isomers phenanthrene and anthracene, the pairs of peaks were totally unresolved (Fig. 5a). Their resolution was improved by working in the stable nematic phase with a programmed temperature (Fig. 5b): The column was maintained during $12 \mathrm{~min}$ at $118{ }^{\circ} \mathrm{C}$, then heated to $180{ }^{\circ} \mathrm{C}$ at $10{ }^{\circ} \mathrm{C} / \mathrm{min}$. Acenaphthene was thus separated from acenaphthylene with a resolution of 1.5. Besides, phenanthrene was well resolved from anthracene ( $\operatorname{Rs}_{4-5}=3.2$ ); anthracene which presents a more linear geometry was more retained than phenanthrene as it was previously observed on other LCSPs with a nematic mesophase $[30,3,28]$.

It must be remembered that the separation of phenanthrene from anthracene remains not easy to achieve [3,31] with a conventional GC stationary phase (eg. 5\% phenyl-methylpolysiloxane column [31]) and was not observed with a previously investigated nematic LCSP by Perez et al. [32]. Their elution order in the mesophase can be explained by the molecular organization in the liquid crystal state. Indeed, in a nematic phase, the molecules orient themselves spontaneously in a privileged direction and can move in the three directions of space, while preserving one-dimensional order. Nematic molecules thus form channels and make it easier for the most linear probes to insert into the mesophase. The order of elution observed on BHOBP confirmed its nematic structure.

The analysis of these five PAHs was also performed into the nematic phase, in isothermal conditions at $118{ }^{\circ} \mathrm{C}$. A first mixture of Acenaphthene (1), Acenaphthylene (2) and Fluorene (3) was eluted in 21 min with a resolution Rs $1-2=1.5$. A second mixture of Phenanthrene (4) and Anthracene (5) was well resolved too (Rs $4-5=6.4$ ) but the separation was achieved in 92 min which is too long. It seems obvious that at $80{ }^{\circ} \mathrm{C}$ in the supercooled BHOBP, this analysis would be even longer. Therefore, this analysis was carried out in the nematic phase through the temperature programming described above.
The last two examples will show why it is interesting to work with the supercooled BHOBP. To separate rather volatile organic compounds (VOC), we took advantage of the geometrical selectivity of the supercooled nematic liquid crystal revealed at $80{ }^{\circ} \mathrm{C}$.

\subsubsection{Analysis of ortho-, meta- and para- isomers of cresol}

These volatile isomers were not retained when eluted in the solid phase at $80{ }^{\circ} \mathrm{C}$ (Fig. 6a). In the stable liquid crystal stationary phase at $118{ }^{\circ} \mathrm{C}$, they were weakly retained. The retention factors were below 0.33 and para- and meta- isomers were totally unresolved (Fig. 6b). The three isomers of cresol were well resolved in the supercooled BHOBP at $80{ }^{\circ} \mathrm{C}$ (Fig. 6c): The resolution was 1.5 for the close boiling isomers, para- and meta- cresols and the molecule having the greater length-to-width ratio, the para- isomer was more retained $\left(\mathrm{k}_{3}==1.66\right)$. This order of elution confirmed again the nematic structure of the supercooled mesophase [3]. On the other hand, the difference of retention between the solid phase at $80{ }^{\circ} \mathrm{C}$ and the supercooled nematic BHOBP at $80{ }^{\circ} \mathrm{C}$ was confirmed with the three isomers. There was an increase of about $1733 \%, 2071 \%$ and $2271 \%$ of the retention factor, respectively, for ortho-cresol, meta-cresol and para-cresol.

It is interesting to note that, according to literature, para- and meta- isomers of cresol could be separated only on certain liquid crystal phases. Witkiewicz Z. (1978) asserted that with the four LCSPs azoxy-compound he tested, elution of cresols took several hours with a huge broadening of the peaks [15]. Judeinstein et al. (1999) described "a bad separation" of meta- and para- cresols [24]. Para- and meta- cresols were not separated on the nematic phases LCC [33], LCC1, LCC3, LCC4 [27], LCST [28]; only a low resolution was obtained on the LCUT [28] nematic phase. The only report of a separation of the three isomers involved DOE-DOE and DOE-C7 in the nematic range of temperature and has been related to the dissolution thermodynamics of the solutes [26]. 


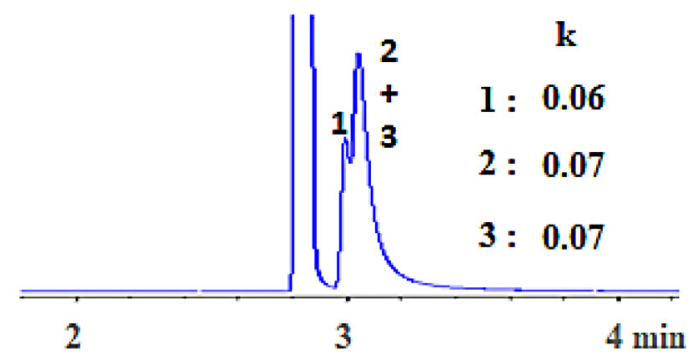

(c) $80^{\circ} \mathrm{C}+\mathrm{N}$

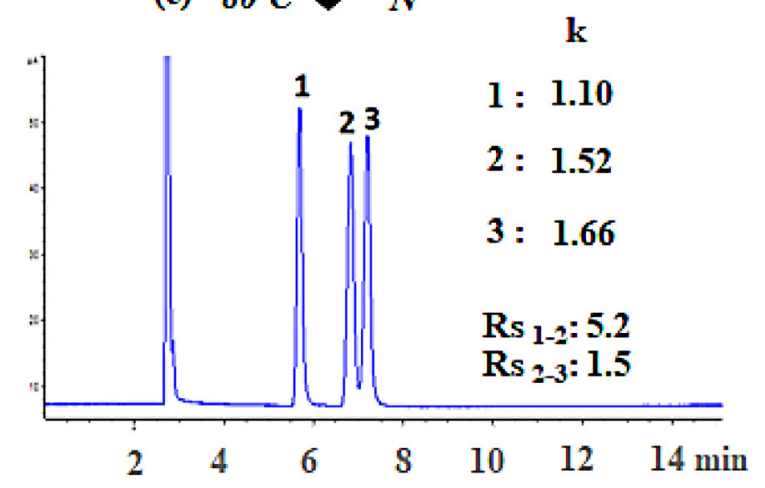

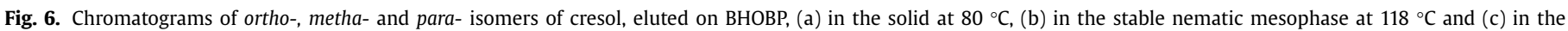
supercooled nematic mesophase at $80{ }^{\circ} \mathrm{C}$. (1) o-cresol; (2) m-cresol; (3) p-cresol.

\subsubsection{Analysis of cis and trans decalin}

These geometrical isomers were not retained and unresolved when eluted in the solid phase at $80{ }^{\circ} \mathrm{C}$ (Fig. 7a: $\mathrm{k}_{\text {cis,trans }}==0.02$ ) and at $118{ }^{\circ} \mathrm{C}$ in the stable liquid crystal stationary phase (Fig. 7b: $\mathrm{k}_{\mathrm{cis}, \text { trans }}==0.04$ ). In the supercooled BHOBP at $80^{\circ} \mathrm{C}$, cis and trans isomers of decalin were well separated with a resolution close to 2 (Fig. 7c). The selectivity of BHOBP stationary phase was well improved in the supercooled state at $80{ }^{\circ} \mathrm{C}\left(\alpha_{\text {cis,trans }}\right.$ was 1.46$)$, certainly because of the increase of "BHOBP molecules-probe solutes" interactions. Indeed, there was an increase of retention factor of about $550 \%$ and $850 \%$ from the solid phase at $80{ }^{\circ} \mathrm{C}$ to the supercooled nematic BHOBP at $80{ }^{\circ} \mathrm{C}$, respectively, for trans- decalin and cis-decalin.

However, the studied liquid crystal phase exhibited an unusual behavior for the separation of this couple of isomers. Indeed, the elution order experimentally observed in the present study, i.e. trans isomer (the more linear and volatile isomer) then cis, was the opposite of that generally reported in literature with a liquid crystal stationary phase of nematic type [34,32,24,25,3]. In previous works [34,32,24,25,3], the separations were achieved in the nematic mesophase at a temperature higher than $100{ }^{\circ} \mathrm{C}$. The order of elution observed in this work on BHOBP was only found with one nematic mesophase on which the separation was achieved below $100{ }^{\circ} \mathrm{C}$, at $83{ }^{\circ} \mathrm{C}[35,3]$. To explain this order of elution, it is possible to consider that the mesogenic molecules of BHOBP present a specific arrangement, at specific temperatures. In these conditions, there must be "specific interactions" between the LCSP and the probes which may influence the separation. Although, the temperature influences the retention in gas chromatography and the elution time depends, in part, on the volatility of the solutes analyzed, the temperature could also influence the spatial molecular arrangement of the stationary phase. Otherwise, with a mesophase, most of the separations described in literature prove that the geometric selectivity generally dictates the elution order [33,31,24,25,1-5].

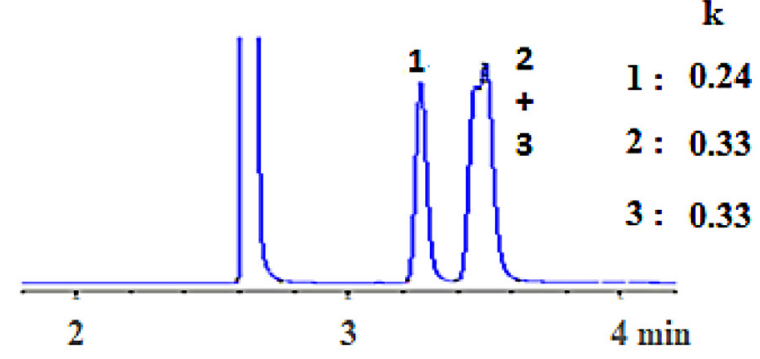

\section{(a) $80^{\circ} \mathrm{C}$}

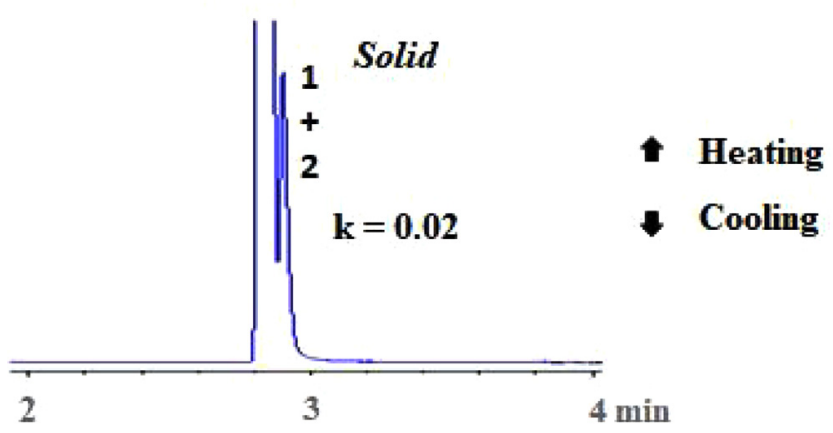

(b)

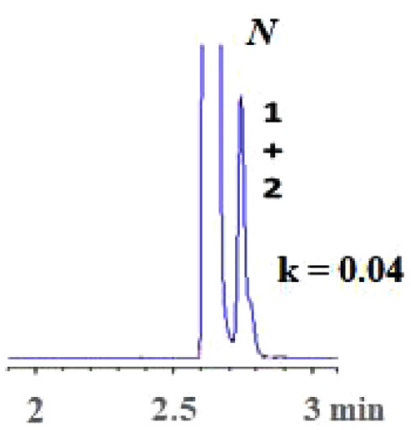

1 Heating

7 Cooling $\mathbf{k}$ 
This separation achieved on BHOBP was confirmed and controlled many times, by injecting standard solutions of each isomer and then mixtures of the two isomers in various proportions.

\subsubsection{Evaluation of the column efficiency}

The efficiency of BHOBP column was estimated, through examples of well-retained probe solutes in the stable nematic phase at $150{ }^{\circ} \mathrm{C}$ as well as in the supercooled nematic phase at $80{ }^{\circ} \mathrm{C}$. At $150{ }^{\circ} \mathrm{C}$, phenanthrene and anthracene (respectively $k=6.8$ and $k=7.8$ ) led to about 330 then 400 plates/m; in the supercooled phase at $80{ }^{\circ} \mathrm{C}$, the plate number measured on 3,4-diMePhOH $(k=3.4)$ and $n$-hexadecane $(k=3.8)$ was, respectively, about 500 and 920 plates $/ \mathrm{m}$. Indeed, in literature the stationary liquid crystal phases are often described as being of low efficiency [2,3]. In this work, the modest efficiency of the column was highly compensated for by the geometric selectivity of the stationary liquid crystal phase.

\section{Conclusion}

Nowadays, all the works carried out on new LCSPs try to take advantage only of the geometric selectivity in the liquid crystal appearing after the melting point. In the present work, a new synthesized stationary phase the "BHOBP» presenting a supercooled nematic phase which was stable over more than 7 weeks at $80{ }^{\circ} \mathrm{C}$, was used at a relatively low temperature. It is the first paper in which a very stable supercooled state of LCSP is described. Thus, a new approach in the analytical separation was proposed using the supercooled nematic state. It is interesting to note that the supercooled state of the liquid crystal was much more stable in the chromatographic column than outside of the column. The new stationary phase BHOBP showed a geometrical selectivity, especially for cis-trans isomers. In the stable nematic phase, above the melting point, it allowed the resolution of isomers having a low volatility. Particularly, phenanthrene and anthracene which are not easily resolved on conventional GC stationary phases were well separated. The presence of the supercooled nematic phase expanded the analytical capabilities of BHOBP and improved its shape selectivity. In these conditions, separations of volatile isomers which were not separated in the stable nematic phase could be achieved. The new stationary phase used in the supercooled state can open the way to novel interesting separations that have never been reached with other stationary phases even liquid crystal ones in the analysis of low boiling organic compounds. Following this work, the kinetics of separations will be investigated together with the influence of the amount of the liquid crystal in the column including on its supercooling state. The capabilities (selectivity) should also be demonstrated on other compounds. Another perspective could be to integrate BHOBP stationary liquid crystal phase in a 2D GC approach for complex mixtures. Moreover, it would be also interesting to develop other phases with new selectivities.

\section{Declaration of Competing Interest}

The authors declare that they have no known competing financial interests or personal relationships that could have appeared to influence the work reported in this paper.

\section{CRediT authorship contribution statement}

Faïza Ammar Khodja: Data curation, Methodology, Writing original draft, Writing - review \& editing. Patrick Sassiat: Methodology. Mohamed Hanafi: Methodology. Didier Thiebaut: Supervision, Writing - review \& editing. Jérôme Vial: Supervision, Writing - review \& editing.

\section{Acknowledgements}

Faïza AMMAR KHODJA wishes to express her thanks to Mrs. Saliha GUERMOUCHE and Mr. Moulay Hassene GUERMOUCHE for the experience gained from them, at the Laboratory of Chromatography of USTHB (Algiers), in chromatography in general and more particularly in the chromatographic study of liquid crystal stationary phases, to Mr. Jean-Pierre BAYLE the designer of several families of liquid crystals including that of the BHOBP, who guided and accompanied her for the synthesis of BHOBP, at the ICMMO NMR Laboratory, Paris Sud University, Orsay, France, to Mr. Jean-Pierre BAYLE and Mr. Patrick JUDEINSTEIN for the discussions about the thermal behavior of BHOBP liquid crystal.

\section{Supplementary materials}

Supplementary material associated with this article can be found, in the online version, at doi:10.1016/j.chroma.2019.460786.

\section{References}

[1] Z. Witkiewicz, Liquid-crystalline stationary phases for gas chromatograhy, J. Chromatogr. 251 (1982) 311-337.

[2] Z. Witkiewicz, Application of liquid crystals in chromatography, J. Chromatogr. 466 (1989) 37-87.

[3] Z. Witkiewicz, J. Oszczudłowski, M. Repelewicz, Liquid-crystalline stationary phases for gas chromatography, J. Chromatogr. A 1062 (2005) 155-174.

[4] E. Ghanem, S. Al-Hariri, Separation of isomers on nematic liquid crystal stationary phases in gas chromatography: a review, Chromatographia 77 (2014) 653-662

[5] H. Grajek, Z. Witkiewicz, M. Purchała, W. Drzewiński, Liquid crystals as stationary phases in chromatography, Chromatographia 79 (2016) 1217-1245.

[6] G Friedel, Les états mésomorphes de la matière, Ann Phys (Paris) S273 (1922).

[7] G.W. Gray, Molecular Structure and the Properties of Liquids Crystals, Academic Press, New York, 1962

[8] P.G. De Gennes, The Properties of Liquid Crystals, Clarendon Press, Oxford, 1974

[9] D. Demus, H. Demus, H. Zaschke, Flusige kristalle in tabellen, Leipzig (1974).

[10] A.M. Levelut, Structures des phases mésomorphes formées de molécules discoïdes, Journal de Chimie Physique 80 (1983) 149-161.

[11] G.W. Gray, J.W. Goodby, Smectic Liquid Crystals, Leonard Hill, 1984

[12] J.P.F. Lagerwall, G. Scalia, A new era for liquid crystal research: applications of liquid crystals in soft matter nano-, bio- and microtechnology, Curr. Appl. Phys. 12 (2012) 1387-1412.

[13] D Andrienko, Introduction to liquid crystals, J Mol Liq 267 (2018) 520-541.

[14] S. Wasik, S. Chesler, Use of a nematic liquid crystal for the gas-liquid chromatographic separation of naphthalene homologues, J. Chromatogr. 122 (1976) $451-458$.

[15] Z. Witkiewicz, Z. Suprynowicz, J. Wojcik, R. Dabrowski, Separation of the isomers of some disubstituted benzenes on liquid-crystalline stationary phases in small-bore packed micro-columns, J. Chromatogr. 152 (1978) 323-328.

[16] R. Lester, D.R. Hall, 4-(p-methoxycinnamyloxy)-4'-methoxyazobenzene: a nematic liquid crystal for the gas-liquid chromatographic analysis of the stereochemistry of lepidopterous sex pheromones and related unsaturated fatty alcohols and derivatives, J. Chromatogr. 190 (1980) 35-41.

[17] T.J. Betts, Possible value of a liquid crystal stationary phase for the gas chromatographic study of aromatic constituents of essential oils, J. Chromatogr. 513 (1990) 311-314.

[18] T.J. Betts, C.M. Moir, A.I. Tassone, Use of a liquid crystal stationary phase at temperatures below its melting point for the gas chromatographic study of some volatile oil constituents, J. Chromatogr. 547 (1991) 335-344.

[19] W. Zhou, R. Fu, R. Dai, Z. Huang, Y. Chen, Use of a long-spacer-side-chain liquid crystalline polysiloxane containing a crown ether as a stationary phase for capillary gas chromatography, J. High Resol. Chromatogr. 17 (1994) 719-722.

[20] G.J. Price, S.J. Hickling, I.M. Shillcock, Applications of inverse gas chromatography in the study of liquid crystalline stationary phases, J. Chromatogr. A 969 (2002) 193-205

[21] S.V. Blokhina, A.V. Sharapova, M.V. Ol'khovich, Supercooled smectic phases of p-n-Alkoxycinnamoyloxy-p'-Cyanoazobenzenes in gas-liquid chromatography, J. Anal. Chem. 59 (4) (2004) 354-357.

[22] W. Marciniak, Z. Witkiewicz, Effect of the amount of liquid crystal and type of support on some properties of the liquid crystalline stationary phase-support system, J. Chromatogr. 207 (1981) 333-343.

[23] E. Matisová, D. Hudec, J. Garaj, G. Kraus, M. Schierhorn, A. Isenberg, The dependence of the properties of liquid crystals on the film thickness and surface quality of capillary columns, Chromatographia 20 (10) (1985) 601-608. 
[24] P. Judeinstein, P. Berdagué, J.P. Bayle, E. Rogalska, M. Rogalski, D. Petit-Jean, M.H. Guermouche, Synthesis and properties of two new liquid crystals: an analytical and thermodynamic study, J. Chromatogr. A 859 (1999) 59-67.

[25] F. Ammar-Khodja, S. Guermouche, M.H. Guermouche, P. Berdagué, J.P. Bayle, Gas chromatographic properties of some liquid crystals containing dioxyethylene ether terminal chains, Chromatographia 50 (5/6) (1999) 338-345.

[26] F. Ammar-Khodja, S. Guermouche, M.H. Guermouche, E. Rogalska, M. Rogalski, P. Judeinstein, J.P. Bayle, A thermodynamic approach to understanding liquid crystal selectivity in gas chromatography, Chromatographia 57 (3/4) (2003) 249-253.

[27] A. Addoun, O. Ferroukhi, M. Dahmane, S. Guermouche, J.P. Bayle, M.H. Guermouche, Three nematogen azobenzene-based stationary phases for capillary GC: synthesis and comparative study, Chromatographia 77 (2014) 1367-1377.

[28] O. Ferroukhi, A. Addoun, S. Guermouche, J.P. Bayle, M.H. Guermouche, Evaluation of the effect of citronellol group on functionalized mesogenic materials by capillary GC, Chromatographia 78 (2015) 1251-1261.

[29] M. Dahmane, F. Athman, S. Boudah, S. Sebih, M.H. Guermouche, J.P. Bayle, End group effect on the thermal and gas chromatographic properties of some para-substituted non-symmetrical nematogens, Chromatographia 79 (2016) 885-902.
[30] P. Berdagué, F. Perez, J. Courtieu, J.P. Bayle, O. Abdelhadi, S. Guermouche, M.H. Guermouche, Gas chromatographic study of the thermal and analytical properties of a nematic liquid crystal and its cupric complex, J. High Resol. Chromatogr. 18 (1995) 304-308.

[31] D.L. Poster, L.C. Sander, S.A. Wise, Chromatographic methods of analysis for the determination of PAHs in environmental samples, $\mathrm{PAHs}$ and related compounds, in: A.H. Neilson (Ed.), Handbook of Environmental Chemistry, 3, Springer-Verlag, Berlin Heidelberg, 1998, pp. 77-135.

[32] F. Perez, P. Berdagué, J. Courtieu, J.P. Bayle, S. Boudah, M.H. Guermouche, Comparison of two azobenzene liquid crystal stationary phases in open tubular column gas chromatography, J. Chromatogr. A 746 (1996) 247-254.

[33] M. Dahmane, F. Athman, S. Sebih, M.H. Guermouche, J.P. Bayle, S. Boudah, Comparison of analytical properties of two liquid crystalline stationary phases by capillary GC, Chromatographia 70 (3/4) (2009) 489-495.

[34] A. Meddour, J. Courtieu, W. Abdelhadi, S. Guermouche, M.H. Guermouche, Gas chromatographic properties of two thermotropic Poly(L-glutamates) with long alkyl side chains, Chromatographia 43 (7/8) (1996) 387-392.

[35] J. Krupčík, M. Valachovičová, G. Kraus, Evaluation of shape selectivity of liquid crystals in capillary gas chromatography, J. Chromatogr. A 665 (1994) 111-116. 